\title{
HaNPV persistence improvement using UV protectants and adjuvants
}

\begin{abstract}
HaNPV alone only causes lower larval mortality. However, in combination with adjuvants increases the larval mortality acting as gustatory or phago-stimulant, whereas, UV protectants increase the stability and longer persistence of $H a \mathrm{NPV}$ in field conditions. Boric acid and folic acid acts dual role of adjuvant and UV protectant. $H a \mathrm{NPV}$ in combination with UV protectants and adjuvants is more effective than $H a \mathrm{NPV}$ alone under field conditions. It is also clear that spray can be taken up during evening hours to prevent exposure of $H a \mathrm{NPV}$ directly to sunlight and evaporation, which also helps in longer residual of $H a \mathrm{NPV}$ in field.
\end{abstract}

Volume 6 Issue 2 - 2017

\author{
Divya C,' Hiren G Kanara, ${ }^{2}$ Jethva DM³ \\ 'Department of Entomology, India \\ ${ }^{2}$ Grassland Research Station, India \\ ${ }^{3}$ Biocontrol Research Laboratory, Junagadh Agricultural \\ University, India
}

Correspondence: Hiren G Kanara, Grassland Research

Station, India, Email kanarahiren I@gmail.com

Received: October 12, 2016 | Published: January 30, 2017

\section{Introduction}

Among the food crops, pulses are an important group which occupies a unique position in the world of agriculture by virtue of their high protein content. In pulses, chickpea (Cicer arietinum Linnaeus) is one of the important crops grown in rabi season. It is commonly known as "Bengal gram" or "Gram" which is mainly grown in the Indian sub-continent, Western Asia and in many tropical countries. It is a self- pollinated crop and belongs to the sub family Papilionaceae of the family Leguminaceae. ${ }^{1}$ In India, chickpea occupies a predominant position and grown in about 8.70 million hectares with a production of 8.88 million tons with productivity of $1021 \mathrm{~kg} / \mathrm{ha}$ during rabi, 2012-13. ${ }^{2}$ The production of cereals has increased manifold in the recent past but that of pulses has remained more or less static. Insect pests are probably the main factor limiting the grain legume yields. More than 150 species of insects are known to attack pulse crops in India and of these, about 25 causes serious damage to monsoon and winter pulse crops. ${ }^{3}$ Out of them, the gram pod borer, Helicoverpa armigera(Hubner) (Lepidoptera: Noctuidae) is a most cosmopolitan and polyphagous pest which attacks numerous crops of agricultural importance and widely distributed for the tropic and sub-tropic.

\section{HaNPV (Helicoverpa armigera Nucleo Polyhedrosis Virus)}

The indiscriminate use of pesticides for the last 40years has almost eliminated natural enemies from many crop eco-systems, created complications of environment pollution, pest resurgence and insecticide resistance. ${ }^{4}$ This scenario has led to consider the potential of biological control as a component of pest management. Biopesticides based on baculo viruses group especially the nucleo polyhedrosis virus (NPV) offers great scope against $H$. armigera. NPV is known for high epizootic levels and is naturally occurring obligate parasite, self- perpetuating, safe to natural enemies due to host specificity and environmental friendly.

\section{Constrain in Usage of Biopesticides}

The important constrains in effective utilization of insect viruses is the lack of persistence in field. The primary factor responsible for inactivation under field conditions has been demonstrated to be the ultraviolet (UV) radiation from the sunlight in the spectral range of
250 to $320 \mathrm{~nm}$ and loss of efficacy is the most striking feature of the action of UV irradiation on virions. ${ }^{5,6}$

\section{How to Improve Persistence in Field Condition?}

The common practice of addition of adjuvants and UV protectants which improved efficacy of microbial insecticides, decreases sunlight degradation, evaporation and increases wettability and also act as gustatory stimulant. ${ }^{7}$ Deotale et al. ${ }^{8}$ recorded the highest reduction in larval population of $H$. armigera in the $H a \mathrm{NPV}+$ folic acid followed by $\mathrm{HaNPV}+$ ranipal. He also reported that the addition of folic acid or ranipal with $H a \mathrm{NPV}$ spray solution avoid deterioration of the NPV in the sunlight and bring about more reduction in the population of H. armigera.

\section{Conclusion}

$\mathrm{HaNPV}$ alone only causes lower larval mortality. However, in combination with adjuvants such as Milk powder and Jaggery increases the larval mortality acting as gustatory or phago-stimulant, whereas, UV protectants like Ranipal and Robin blue increases the stability and longer persistence of $\mathrm{HaNPV}$ in field conditions. Boric acid and folic acid acts dual role of adjuvant and UV protectant. Thus, it is clear that the $H a \mathrm{NPV}$ in combination with UV protectants and adjuvants is more effective than $\mathrm{HaNPV}$ alone under field conditions. It is also clear that spray can be taken up during evening hours to prevent exposure of $\mathrm{HaNPV}$ directly to sunlight and evaporation, which also helps in longer residual of $\mathrm{HaNPV}$ in field.

\section{Acknowledgements}

None.

\section{Conflict of interest}

The author declares no conflict of interest.

\section{References}

1. Bentham G, Hooker JP. Genera platinum (Genera of plant). 1970;1:324.

2. Anonymous. Directorate of Economics and Statistics, Department of Agriculture and Co- operation; 2013. 
3. Bindra OS. Insect pests of pulse crops. Indian Farming. 1968;17(11):1214.

4. Ma DL, Gordh G, Zalucki MP. Toxicity of biorational insecticides to Helicoverpa spp. and predators in cotton fields. International Journal of Pest Management. 2000;46:237-240.

5. Bullock HR. Persistance of Heliothis nuclear polyhedrosis virus on cotton foliage. Journal of Invertebrate Pathology. 1967;9:434-436.

6. Ignoffo CM, Hostetter DL, Brooks WM. Inactivation of representative species of entomopathogenic viruses, bacterium, fungus and protozoan by an ultraviolet light source. Environmental Entomology. 1977;6:411415 .
7. Yelshetty S, Gopali JB, Patil BV, et al. Effect of different adjuvants in enhancing the efficacy of $\mathrm{Ha}$ NPV against $H$. armigera in pigeonpea. Karnataka Journal of Agricultural Sciences. 2009;22(3):502-503.

8. Deotale RO, Dawane PN, Biswane KD, et al. Effectiveness of UV protectant on the activity of NPV against Helicoverpa armigera(Hübner) on Chickpea. Journal of Entomological Research. 2007;31(1):33-35. 